Comunicação. Escola. Interação. Resolução colaborativa de problemas. Tecnologia.

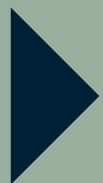




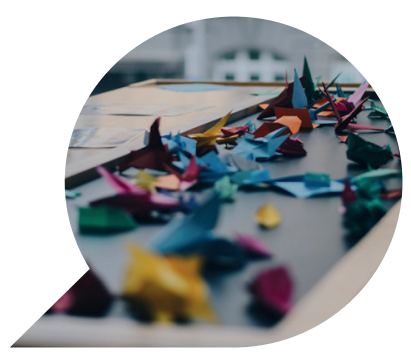

\section{A interação como potência comunicativa na escola: um estudo sobre a resolução colaborativa de problemas}

La interacción como potencia comunicativa en la escuela: un estudio sobre la resolución colaborativa de problemas

Interaction as communicative power in school: a study on collaborative problem solving

LYANA VIRGÍNIA THÉDIGA DE MIRANDA ${ }^{1}$

MAGDA PISCHETOLA ${ }^{2}$

Resumo: O processo comunicativo, entendido como transmissão linear de uma mensagem entre um emissor e um receptor, pode ser associado, na educação, às formas de ensino-aprendizagem que incorporam a mesma estrutura comunicacional. $\mathrm{O}$ artigo busca uma compreensão mais profunda dos aspectos relacionais, com foco em uma perspectiva qualitativa e sistêmica da comunicação, cujo centro é o conceito de interação. Com esse escopo, apresenta uma pesquisa qualitativa realizada em duas escolas públicas em Florianópolis (SC) com foco na resolução colaborativa de pro-

1 Doutora em Educação (PPGE/UFSC). Pesquisadora do Núcleo Infância, Comunicação, Cultura e Arte (NICA/UFSC).

2 Professora adjunta do departamento de Educação da Pontifícia Universidade Católica do Rio de Janeiro. Coordenadora do grupo de pesquisa ForTec - Formação docente e Tecnologias. 
blemas (RCP). Como resultado, o estudo demonstra que, ao oportunizar às crianças situações de ensino-aprendizado pautado no entendimento coletivo, na colaboração, e no estimulo da percepção empática, a RCP qualifica-se como uma orientação didática capaz de auxiliar na transformação das práticas pedagógicas, comunicativas e culturais na escola.

Palavras-chave: Comunicação; Interação; Resolução colaborativa de problemas; Tecnologias; Escola.

Resumen: El proceso comunicativo entendido como transmisión lineal de un mensaje entre un emisor y un receptor puede ser asociado en la educación a las formas de enseñanza y aprendizaje que incorporan la misma estructura comunicacional. El artículo busca una comprensión más profunda de los aspectos relacionales, centrándose en una perspectiva cualitativa y sistémica de la comunicación, cuyo centro es la interacción. Con ese objetivo, presenta una investigación cualitativa realizada en dos escuelas públicas en Florianópolis (SC) con foco en la resolución colaborativa de problemas (RCP). El estudio muestra que cuando a los niños se proponen actividades de entendimiento colectivo, colaboración, y con el estímulo de la percepción empática, la RCP se califica como una orientación didáctica capaz de auxiliar en la transformación de las prácticas pedagógicas, comunicativas y culturales en la escuela.

Palabras-llave: Comunicación; Interacción; Resolución colaborativa de problemas; Tecnologías; Escuela.

Abstract: The communicative process understood as the linear transmission of a message between a sender and a receiver can be associated, in education, with teaching and learning methods that incorporate this same communication structure. The article seeks a deeper understanding of relational aspects, focusing on a qualitative and systemic approach to communication, which center is the concept of interaction. With this scope, it presents a qualitative research carried out in two public schools in Florianópolis (SC) focusing on collaborative problem solving. As a result, the study shows that by providing children with teaching and learning situations based on collective understanding, collaboration, and the stimulation of empathic perception, collaborative problem solving qualifies as a possibility to transform didactics, communicative practices and cultural aspects at school.

Keywords: Communication; Interaction; Collaborative problem solving; Technologies; School. 


\section{Introdução}

A reunião de conceitos vindos de áreas do conhecimento aparentemente diversas, como a biologia e a antropologia, é uma forma apropriada para abarcar a comunicação como um todo interligado (BATESON, 1977), que agrega também a escola. Com essa perspectiva, a comunicação pode ser um jogo no qual os parceiros não só trocam mensagens, mas as ajustam, e se ajustam, de acordo com o contexto e no próprio curso da interação. Nesse sentido, a interação é um processo de mútua afetação entre os participantes do processo comunicativo, que envolve pessoas e ambiente. Contudo, para que ele possa ser jogado, cada etapa exige a mobilização de diversas peças, ou melhor, da comunicação competente composta por um agregado de saberes e fazeres.

$\mathrm{Na}$ tentativa de analisarmos os processos educacionais e suas formas comunicativas, buscando questionar a perspectiva mecânica do modelo linear da comunicação e do ensino-aprendizagem e procurando outros caminhos possíveis, propomos adotar uma perspectiva qualitativa e sistêmica da comunicação na escola. A partir dessa abordagem, discutimos as evidências empíricas em que as crianças interagiram e se comunicaram de maneira colaborativa, mobilizando conhecimentos prévios e conexões ativas na busca pela resolução de problemas complexos.

\section{A perspectiva qualitativa e sistêmica da comunicação}

Desde os idos das décadas de 1920 e 1930 - quando se iniciaram os interesses por esboçar uma teoria da comunicação - até os dias atuais, os estudos da comunicação têm se dedicado, principalmente, a analisar os meios que são utilizados como caminho para se emitir as mensagens, os canais para a emissão das mensagens ou os conteúdos emitidos. O sentido "clássico" dentro da chamada communication research (pesquisa em comunicação) aborda o processo comunicativo em termos de uma relação linear entre um emissor que emite uma mensagem ao receptor, no qual o centro da análise está na transmissão, dando ênfase à forma e ao conteúdo da mensagem (WINKIN, 1998). Esse modelo, afirma Mucchielli (2006), valida uma visão teórica e epistemológica do processo comunicativo que é configurado na representação esquemática Emissão-Recepção (E-R). Essa perspectiva reflete o modelo matemático da comunicação, criado com base na engenharia, pautado no padrão quantitativo do processamento de informação e sucessivamente 
transposto para áreas do conhecimento como a Educação. A modelização que se baseia no E-R é, para Mucchielli (2006), uma dificuldade que também pode ser encontrada, por exemplo, na teoria crítica da Escola de Frankfurt, que não tem um modelo esquemático único capaz de conjeturar uma aplicação concreta, ou nos Estudos Culturais, cujo estudo da recepção incorpora o todo comunicativo quando insere o processo de comunicação no interesse das práticas socioculturais.

Ao sugerir um modelo de comunicação orquestral, Gregory Bateson $(1977,1993)$ propõe uma abordagem que privilegia os padrões comunicativos, acentuando o viés pragmático da interação sobre o conteúdo semântico e sintático da mensagem. Com isso, o autor vai (re) incluir no processo comunicativo elementos como a gestualidade, o toque, os cheiros, o espaço e o tempo, considerando a comunicação como um "todo integrado" (WINKIN, 1998), que abarca tanto a comunicação verbal como a não verbal. Na situação de interação, a relação dos atores é o fio condutor das ações compartilhadas. Amparado no pensamento de Bateson e dos demais componentes do chamado "colégio invisível", Yves Winkin (1998) vai propor o modelo orquestral para o que ele considera uma "nova comunicação". Tomando a comunicação como um processo complexo e integrado, Winkin considera a comunicação como um fenômeno social, abandonando a ideia mecânica, maquinal e descontextualizada da concepção matemática.

Com base na concepção ecológica de Bateson e na nova comunicação de Winkin, entendemos que o processo comunicativo é composto por situações de comunicação que se inserem e se configuram em sistemas de comunicação. Integrantes e sistema mais amplo estão ligados por meio das causalidades circulares (e não lineares), no qual o efeito retroage sobre a causa. Nessa dinâmica comunicacional, o viés ecológico e interacional não apresenta nada mais do que a possibilidade de considerar e interpretar a comunicação a partir do seu sentido mais óbvio: o de comunhão, contato, convívio.

$\mathrm{Na}$ definição de Bateson (1993, p. 331), sistema é "qualquer unidade que inclua uma estrutura de retroalimentação (feedback) e, portanto, capaz de processar informação". Nesse sentido, o sistema é um conjunto de determinados elementos integrados por meio da comunicação de tal maneira que, para que possamos entender os seus componentes, é

3 Colégio Invisível é a maneira como Winkin chama o grupo de pesquisadores encabeçados por Gregory Bateson. Apesar de não se encontrarem pessoalmente, eles debatiam e ponderavam a comunicação como um processo social e integrado que abarca o verbal e o não-verbal sempre em determinado contexto. 
necessário compreender as formas como eles se relacionam ou comunicam entre si. Ainda sob a perspectiva de Bateson (1977), a interação ocorre através da comunicação e vice-versa. Contudo, será a comunicação a responsável por dar forma ao sistema ou aos sistemas que integram sistemas como um todo. Com essa abordagem, o foco incide nas relações comunicativas estabelecidas dentro de um contexto, imerso no ambiente, no qual todos os fenômenos devem ser considerados relevantes para a sua compreensão.

Nesse sentido, investigar determinado comportamento em termos de sistemas comunicacionais, segundo o autor, é sinônimo de uma exposição de relações e padrões comunicativos que ocorrem em um dado contexto de circuitos completos, sendo ele mesmo (o contexto) parte de um sistema em constante troca.

A ideia de "contexto" é primária e fundamental para toda comunicação. Nenhuma mensagem nem nenhum elemento de uma mensagem - nenhum evento nem nenhum objeto - tem nenhuma classe de sentido ou de significado se ele se encontra total e inconcebivelmente divorciado de um contexto. Sem um contexto, um evento ou um objeto nem sequer são incertos. (BATESON, 1993, p. 200)

Evidenciado pela circularidade, pela mútua afetação e pela multiplicidade de níveis de interação, será a flexibilidade do sistema - do humano ao tecido social - que lhe garantirá o caráter dinâmico. Para Mucchielli (2006) se pautar em uma perspectiva qualitativa e sistêmica significa considerar a comunicação como um todo no qual as trocas entre os participantes ocorrem dentro de um quadro de ação, em determinada temporalidade, com uma dinâmica própria e significados específicos relacionados ao sistema mais amplo.

A fim de questionar certos sentidos habituais de denotar a interação e a própria comunicação, partimos do pressuposto batesoniano segundo o qual, para que possamos compreender um sistema por meio da interação dos seus componentes é necessário, primeiro, deslocar o foco dos indivíduos para centrar a atenção nos padrões comunicativos mobilizados em um sistema relacional. No interesse da pesquisa comunicativa de base qualitativa e sistêmica, isto significa buscar, especificar e analisar os modelos comunicativos que sustentam a interação em determinado contexto (BATESON, 1993). 


\section{A sociedade comunicativa, as tecnologias e a educação}

Ao chamar a atenção para a necessidade de a unidade básica na análise da comunicação se pautar nos significados construídos pelos sujeitos em uma situação de interação, Mucchielli (2006) traz a ideia de uma sociedade comunicativa, segundo a qual a sociedade é composta por um jogo que inclui forças culturais, econômicas e políticas que interagem e influenciam o uso, a apropriação e a produção de significados com as tecnologias. Consideração esta que se aproxima da ideia de um ecossistema comunicativo e da necessidade em pensar as tecnologias como dimensões desse social, como proposto por Martin-Barbero (2004).

A compreensão da sociedade depende da desconstrução dos mecanismos comunicativos que, por sua vez, não pode ser empreendida por meio de investigações pautadas na causalidade simples e nas relações lineares. Como aponta Martin-Barbero (2004), pensar a comunicação em termos da experiência cotidiana nos auxilia a transformar o sistema comunicativo, adotando sua espessura cultural. Assim, o ponto de vista adotado por Mucchielli (2006) e Martin-Barbero (2004) em relação à apropriação das tecnologias digitais - e no que isso resulta em termos de comportamento no sujeito e na sociedade - permite que questionemos a necessidade de novos métodos para compreendermos os dispositivos em termos de interação, antes de investigarmos as consequências desses usos.

Isso significa ter como interesse: o sujeito e a um só tempo, sua interação com os outros; seu propósito comunicativo, cujo significado surge da situação interacional, e a complexidade contemporânea, amparada pelos múltiplos significados que dependem do ponto de vista do sujeito, do contexto e da forma de apropriação do dispositivo. Dentro do que Martin-Barbero (2004, p. 228) chama de "nova trama comunicativa da cultura", que abarca as modificações das matrizes culturais pela mediação da comunicação com o centro na esfera da identidade e da tecnicidade, há a necessidade de um novo olhar metodológico.

No nosso caso, buscaremos a adoção dessa perspectiva sob o viés pedagógico e didático, articulados à constituição dos problemas de forma dinâmica, ou seja, não os atribuindo unicamente às pessoas em causa, seja em situações globais, em uma organização (como a escola) ou em determinado grupo. Para tal, consideramos que o sistema de interação composto pelos sujeitos e pela escola se constitui como um todo que também inclui as tecnologias digitais. 
A contribuição da perspectiva qualitativa e sistêmica da comunicação está na possibilidade de refletirmos sobre a instauração de competências comunicativas, mobilizadas em situações ativas e interacionais na escola. Com essa base, nos interessa investigar de que forma a busca do grupo pela solução de um problema complexo se configura como maior do que a soma das realizações individuais dos membros envolvidos. Desta maneira, o foco do nosso estudo é o que chamamos de resolução colaborativa de problemas (RCP) na escola. Nossa hipótese é que a RCP se insere na perspectiva qualitativa e sistêmica da comunicação ao ser, ela mesma, configurada como uma situação de interação entre os diversos atores/participantes envolvidos.

\section{A resolução colaborativa de problemas: relato de uma pesquisa}

Consideramos a resolução colaborativa de problemas (RCP) uma possibilidade de ensino-aprendizagem pautada na coatividade (FRAUENFELDER et al., 2013) entre os diversos participantes envolvidos e na multiplicidade comunicativa que permite um processo comunicativo dialógico, valorizando as trocas verbais e não-verbais. Com isso, a RCP qualifica-se por possibilitar a construção e a manipulação dos significados pelos alunos, levando em consideração uma combinação de domínios - culturais, sociais, tecnológicos, cognitivos e emocionais. A característica principal da RCP está no esforço do grupo (professor, alunos, pesquisadores, escola em si) em construir uma compreensão coletiva e buscar um entendimento comum, negociando suas possíveis soluções através de um sistema de comunicação total (BATESON, 1977)4.

Com base na proposta do pragmatista John Dewey (1980) - um dos primeiros educadores a pensar a resolução de problemas no contexto escolar -, resolver problemas de forma didática diz respeito à construção de um ambiente ativo de aprendizagem que se pauta nas etapas básicas do método científico. As atividades didáticas podem ser organizadas em forma de situações-problema que seguem os passos do processo científico: parte das observações e da formulação de perguntas; passa para a formulação de hipóteses e a realização de experimentação; até chegar à confirmação ou refutação da hipótese inicial, que segue para a formulação de novas questões. Para Watras (2011), o entendimento de

4 A proposta de RCP aqui adotada ultrapassa o entendimento da resolução de problemas como práticas didáticas que se focam no resultado, muitas vezes descolados do contexto dos alunos, e voltadas para um conteúdo de uma determinada área, comumente, a matemática. (BRASIL, 1998) 
Dewey de que o pensamento humano é derivado da experiência - que ocorre quando uma pessoa percebe a resposta que é criada no meio ambiente à sua ação - é o que embasa a relação entre os métodos didático e científico.

Henry Jenkins (2009) também apresenta a RCP como uma oportunidade de os alunos realizarem um trabalho conjunto no enfrentamento de desafios, na conclusão de tarefas e, sobretudo, no desenvolvimento de novos conhecimentos e na mobilização de competências. Dessa forma, a RCP é, no seio da cultura participativa, uma das possibilidades para se construir uma ponte entre a aprendizagem formal e informal. Além disso, é um "espaço" para a mobilização de competências - relacionais, comunicativas e midiáticas - promovidas para que possamos participar de forma plena na contemporaneidade, partindo sempre da experiência.

Conhecer os processos de mútua afetação entre sujeito e ambiente, bem como nos aproximarmos dos preceitos da cognição incorporada e situada, nos ajuda a perceber as ações de retroalimentação (feedback) que ocorrem de maneira interativa e colaborativa. A ideia que nos aproxima de tais concepções é a de que os participantes de uma interação social não só podem compreender suas mútuas afetações, como também podem compartilhar essa percepção.

\section{Metodologia de pesquisa}

Para alcançar o objetivo geral da pesquisa - investigar a mobilização de competências comunicativas entre crianças na RCP na escola -, foi realizado, durante o ano letivo de 2015, um estudo de cunho qualitativo em duas escolas públicas situadas na Ilha de Santa Catarina: a Escola Básica Vitor Miguel de Souza (a seguir denominada Escola 1) e o Colégio de Aplicação da Universidade Federal de Santa Catarina - UFSC (a seguir denominada Escola 2). Segue um breve perfil das escolas pesquisadas:

\section{- Escola 1}

Seguindo o caráter de continuidade da pesquisa, na Escola 1 a turma investigada foi a mesma na qual foi realizada a pesquisa de mestrado, em 2012 (MIRANDA, 2013). A escola atende um público que, em sua maioria, é composto por estudantes de classe média baixa que habitam no próprio bairro. Cursando o sexto ano, os alunos, 28 ao total, 
estavam na faixa de 10-12 anos e cerca de metade da turma era composta de sujeitos diferentes dos que participaram da pesquisa anterior. Para a investigação, seguimos a indicação da diretora quanto à escolha do professor, o que nos oportunizou trabalhar com a disciplina de História.

Apesar de a escola ter participado do Programa Um Computador por Aluno (PROUCA) ${ }^{5}$ no passado, as tecnologias digitais não estavam no dia-a-dia didático. Ainda assim, percebemos o consumo midiático e o uso dos dispositivos nas falas e comportamentos dos alunos.

\section{- Escola 2}

Na Escola 2, o perfil dos alunos não era homogêneo. Isso se dá devido ao processo de entrada na escola, que ocorre por meio de sorteio. Pela especificidade de ser uma escola inserida em uma Universidade Federal e, por isso, receber muitos projetos, pesquisas e estagiários, a turma composta por 31 alunos (entre 11-12 anos) parecia acostumada às intervenções, aos estímulos e à presença de pessoas estranhas à rotina da escola. Com essa disposição, os alunos se envolveram de forma rápida com as propostas. A perspectiva receptiva das professoras possibilitou conciliarmos as aulas de Português e História, o que acrescentou uma perspectiva interdisciplinar às intervenções didático-pedagógicas. A escola também nos oportunizou utilizar a rede de internet da UFSC nas aulas.

$\mathrm{O}$ arcabouço da pesquisa empírica contou com as seguintes etapas, realizadas nas duas escolas:

- Observação participante com o auxílio de um roteiro de observação;

- Intervenção didático-pedagógica seguindo planejamentos distintos, sempre de acordo com o conteúdo trabalhado pelo professor e tendo como base a perspectiva ativa, deslocando o foco do professor e/ou do aluno e situando-o nas interações possíveis dentro de um ambiente de aprendizagem;

- Grupos Focais realizados com propostas diferentes em cada escola buscando uma avaliação propositiva por meio da investigação sobre o trabalho colaborativo e a compreensão da visão conjunta na resolução dos problemas.

Partindo das etapas da organização do material, bem como da pertinência da análise qualitativa do que foi selecionado em relação aos objetivos da pesquisa, realizamos a síntese estruturada em três categorias

5 Informação sobre o programa disponível em: http://www.fnde.gov.br/programas/proinfo/ eixos-de-atuacao/programa-um-computador-por-aluno-prouca. Último acesso em abril de 2018. 
que possibilitaram a análise integral dos dados obtidos. São elas:

1) Sentidos e expressões da competência comunicativa na RCP, mobilizada pelas crianças com base em uma abordagem didática ativa.

2) Saber informal na RCP e no contexto escolar: a maneira como as crianças percebem, se apropriam e descrevem o percurso trilhado para resolver problemas de forma colaborativa.

3) A RCP na configuração de um sistema-sala de aula.

Para os fins da análise aqui proposta, nos concentramos no segundo e no terceiro aspectos, com vistas a apresentar se e de que forma um contexto de sala de aula pode se constituir como sistema e quais são as interações que, dentro desse contexto, se tornam mais valiosas em termos de RCP.

\section{Análise e discussão dos dados}

A análise fundamentou-se na abordagem metodológica semiótico-situacional (MUCCHIELLI, 2006), caracterizada como um método compreensivo de apreciação dos fenômenos comunicativos levando em consideração as interações dos alunos entre eles, com o professor e com o ambiente escolar. Com o auxílio do Diário de Campo (DC), os dados ali sistematizados foram organizados, codificados, pré-analisados e consolidados, o que permitiu a análise qualitativa por meio de um cruzamento dos processos de comunicação e os elementos contextuais da situação observada.

Os resultados discutidos a partir das categorias destacam as conexões ativadas em colaboração, a necessária adoção da percepção empática, bem como o estímulo da aprendizagem social e culturalmente situada - variáveis qualitativas na mobilização do saber da experiência nesse ambiente. Além dessas, ressaltamos a importância da postura de mediação do professor para a adoção do pensamento ecossistêmico, capaz de configurar a turma como um sistema-sala de aula.

\section{- O saber informal na RCP e no contexto escolar}

Nessa categoria, o foco de discussão está nas possibilidades de as atividades realizadas na escola com as tecnologias digitais se pautarem nas interações entre os saberes prévios dos sujeitos na conformação do ambiente colaborativo. Durante a interação proposta nas atividades, a 
predisposição em negociar ou afirmar aquilo que já se sabe (conhecimento informal) na busca por construir um novo e sistematizado saber (conhecimento formal) reafirma a importância da experiência no processo comunicativo, como lembra Bateson (1977). Para o autor, além de possibilitar a interação e auxiliar na metacognição (aprender sobre aprender de modo contextual), esse saber será aprimorado nas interações que se sucederão, como ocorre, por exemplo, nos espaços de afinidade (GEE; HAYES, 2012).

Caracterizado como um contexto informal de aprendizagens, os espaços de afinidade demandam a capacidade de autorregulação e abertura aos problemas que emergem em interação, aspectos que não são facilmente transferíveis para o contexto formal. Ao contrário, o modo como a escola "administra os desacordos" entre as práticas informais e a formalidade de seus próprios métodos pode limitar a interação a um caráter ocasional. Nesse sentido, foi necessário que o professor assumisse nas atividades propostas na intervenção didática uma postura de mediação entre os saberes formais e informais. Isso possibilitou a construção, a codificação, as trocas e as negociações entre os diversos conhecimentos, além da manipulação dos sistemas simbólicos e culturais naquele ambiente.

A cena a seguir evidencia que uma postura proativa dos alunos não está relacionada somente ao saber prévio que eles possuem. Ela também diz respeito à possibilidade desta conectar-se ao saber agir, interagir e comunicar dentro de um determinado contexto - nesse caso, a escola, quando ela se abre à importância da criação coletiva. Com essa disposição, as atividades de RCP construídas com o foco nas trocas comunicativas permitiram aos alunos imaginar, criar e aplicar novas soluções para o enfrentamento da complexidade em interação com o outro e com o ambiente.

Para projetar o vídeo-estímulo, o professor certificou-se de usarmos os equipamentos da escola (projetor, laptop e caixa de som). Mas não conseguimos inserir o cabo da caixa no laptop. Ao perceber a situação, o aluno PH logo tentou ajudar. Era a primeira vez que o aluno $\mathrm{PH}$ auxiliava na organização e nas explicações. Ele sentiu-se tão a vontade com aquela dinâmica que nas próximas aulas ficava ao meu lado e do professor quando este explicava as atividades, como um especialista, um monitor, um parceiro. (DC - Escola 1, 02/07/2015). 
Para confrontar os problemas, os alunos percorreram, sempre em grupos e de modo geral, os seguintes passos: 1) identificaram e definiram o problema; 2) planejaram, debateram e criaram possibilidades de resolução; 3) testaram as opções disponíveis e negociaram novas soluções; 4) incluíram novos elementos ao problema e a resolução deste, 5) compartilharam com outros colegas as soluções encontradas. Ao solicitar, nos Grupos Focais, que os alunos refizessem os caminhos percorridos e comentassem sobre as estratégias utilizadas para a resolução dos problemas, percebemos, pela maneira como comunicaram, que o compartilhamento das soluções se configurara como parte do trabalho coletivo na sala de aula. Com isso, podemos considerar que as atividades assumiram características de interação tal como ocorre fora da escola, no contexto informal, sobretudo em relação às interações com os colegas.

Nesses cenários, o uso da tecnologia digital emergiu como elemento disparador de uma postura proativa do aluno, acrescentou mais varáveis aos problemas propostos na produção midiática e possibilitou com que os alunos enfrentassem as dificuldades que iam emergindo. Em algumas atividades, as interações e relacionamentos propiciados pela perspectiva ativa e comunicativa durante as atividades configuraram a sala de aula como um sistema, um ambiente compartilhado que possibilitou que os alunos distribuíssem os recursos e os conhecimentos, aprimorando os saberes prévios e criando novos.

\section{- A RCP e a configuração de um sistema-sala de aula}

Nessa categoria, ressaltamos a necessidade de uma postura colaborativa e de se compreender as regras do ambiente, a fim de negociar com elas. Dentro de uma configuração didática que proporciona a participação ativa e comunicativa dos alunos, observamos durante as atividades um conjunto de características mobilizadas no engajamento, na experiência e na coatividade. Compostas pelas trocas comunicativas e tomadas como variáveis na estimulação da escuta atenta, a mobilização da empatia e da conexão ativa contemplam as reflexões sobre situações em que percebemos a necessidade de o grupo se compreender como um sistema para que pudesse colaborar com os colegas em atividades de resolução de problemas.

Dentro das propostas didáticas de RCP, a interação manteve-se como um "espaço" de mútua afetação entre os participantes. Em alguns 
casos, estar aberto e atento ao outro possibilitou a construção de um processo comunicativo dinâmico, permeado pelos constantes ajustes dos sujeitos durante a troca e negociação das mensagens e informações. Para que tal processo ocorresse, foi preciso manter o caráter permeável de negociação das regras que instituem o contexto, nesse caso, a escola e a sala de aula. Desse modo, percebemos que a organização do ambiente incidiu de maneira precisa nas relações que foram instauradas no momento da intervenção, de forma a estruturar as relações ali realizadas.

Partindo dessa constatação, dois cenários podem ser considerados. No primeiro, os alunos não conseguiram apreender, manipular e/ou negociar com as regras do contexto formal e, com isso, não souberam agir dentro de determinada situação que requeria deles uma postura ativa e colaborativa. Já no segundo cenário, além de reconhecerem as regras, os alunos compreenderam que o contexto escolar se constitui como um espaço "individualizante". Nessa situação, os alunos não só não negociaram com as regras do ambiente como optaram por fazer as atividades sozinhos e, assim, não comunicar e colaborar com o outro, uma vez que sabiam que esse era um elemento dispensável na escola.

A cena abaixo evidencia como a configuração do contexto formal e a falta de domínio por parte do aluno para negociar com as suas regras interferiram na postura ativa e colaborativa durante a atividade.

O aluno PE parece tentar entender a lógica do conteúdo do vídeo-estímulo e a relação com a tarefa (construir um storyboard). Ele nos chama para dizer que não conseguirá realizar a tarefa de modo que "fique certo". Explicamos que não era necessário reproduzir o que ele tinha visto no vídeo. Mas a sua própria cobrança em buscar responder de forma correta àquilo que foi solicitado deixou PE desconfortável e preocupado. Ainda assim, ele não negociou uma melhor forma com o colega com o qual fazia dupla. Em toda a etapa de produção ele buscou só a nossa ajuda e a da professora. O colega, aparentando impaciência, acabou unindo-se a outra dupla. PE, mais uma vez, nos chamou, visivelmente preocupado. Desta vez, para dizer que não faria o vídeo. (DC,- Escola 2, 19/05/2015)

Seja na atitude de dependência às regras e finalidades da atividade, tomadas como razão para a sua realização, ou na escolha deliberada de não comunicar e colaborar com o outro, percebemos que as duas ações reforçaram uma "quebra" do vínculo com o colega e com as propostas. Observamos ainda que o foco no resultado de tarefas que geralmente 
se caracterizam pela falta de complexidade de um estímulo que prediz uma resposta, influenciou na maneira como os alunos se comunicaram uns com os outros, nos encaminhamentos dentro da sala de aula e no modo como se posicionaram diante dos problemas que emergiram.

Esses são fatos importantes se considerarmos que a conexão ativa é um dos requisitos da perspectiva qualitativa e sistêmica para mobilização competente da comunicação. Nos dois casos, é significativo levarmos em consideração a interferência do ambiente na construção da interação. Isto é, o fato de o ambiente escolar ser fortemente marcado pela comunicação unilateral e pelo individualismo pode contribuir para a postura de resistência na colaboração e, por consequência, influenciar na mobilização da comunicação e na disponibilidade em auxiliar os outros.

Por outro lado, o interesse em colaborar não só emergiu em interação com o ambiente, como a maneira de comunicar também foi construída e negociada no momento da ação, sobretudo, quando mobilizaram diversos níveis de comunicação (gestos, expressões, movimentos corporais) e extrapolaram o espaço da sala de aula - aumentando a complexidade das situações. Assim, compreende-se que comunicar e colaborar não só incide na busca pelo entendimento, como reforça, no momento da criação coletiva e da coatividade, a perspectiva da sala de aula como um sistema, ou um sistema-sala de aula.

\section{Considerações finais}

$\mathrm{Na}$ escola, a ênfase no desenvolvimento de competências individuais e específicas por meio de métodos didáticos focados no resultado pode ressaltar a competitividade e restringir a colaboração. Assim, ao propormos atividades de resolução colaborativa de problemas (RCP), que dependiam da comunicação em um ambiente fragmentado, esse contexto por vezes resultou em falta de interesse, na indisponibilidade para a colaboração e na ausência da consideração das diferenças. Tais posturas evidenciam a insuficiente capacidade da escola, como ambiente, de promover a adoção de outros modos de ver, estar e comunicar com o outro.

Ao contrário do que ocorre nas atividades rígidas e altamente gerenciadas - que deixam pouca margem para a emergência de problemas e de um agir criativo -, os alunos puderam vivenciar uma certa "desestruturação" do espaço e tempo da sala de aula nas propostas de 
RCP pautadas na perspectiva qualitativa e sistêmica da comunicação. Chamamos essa "nova configuração" de sistema-sala de aula, que abriu caminho para que o professor questionasse certos dogmatismos metodológicos, e para que os alunos participassem e negociassem a construção de novas normas dentro da sala de aula.

Como pudemos observar, esse foi um ponto importante para que os alunos se sentissem confiantes e autônomos para explorar os diversos conhecimentos e compartilhar as dúvidas.. Isso porque, mesmo com uma proposta baseada no modelo comunicativo qualitativo e sistêmico e na didática ativa, a constante tensão com as regras do ambiente escolar pode confundir a interpretação do aluno e o seu sentido de colaboração, participação, proatividade e empatia.

Outro ponto importante foi o papel do professor como um mediador entre "dois mundos" - o contexto formal e informal. Essa postura foi de grande importância para que os alunos pudessem mobilizar seus saberes da experiência no cenário da escola, dentro da perspectiva ativa da didática, e na constituição da sala de aula como um ambiente comunicativo propício às ações colaborativas, no qual as aprendizagens foram construídas, refletidas e compartilhadas em interação.

Por fim, compreendemos que a configuração do sistema-sala de aula e a mediação do professor envolvem práticas didáticas capazes de questionar um referente egocêntrico e transformá-lo em alocêntrico. Dessa forma, será possível conectar o professor aos alunos, os alunos uns aos outros, bem como a escola ao mundo.

\section{REFERÊNCIAS}

BATESON, Gregory. Una unidad sagrada. Passos ulteriores hacia una ecologia de la mente. Barcelona: Gedisa, 1993

BATESON, Gregory. Steps to an ecology of mind. Library of Congress Cataloging-inPublication Data, 1977

BRASIL, Secretaria de Educação Fundamental. Parâmetros Curriculares Nacionais $3^{\circ}$ e $4^{\circ}$ ciclos do Ensino Fundamental: Matemática. Brasília: MEC/SEF, 1998

DEWEY, John. Os Pensadores. São Paulo: Abril Cultural, 1980.

FRAUENFELDER, Eliana et al. Bio-education, simplexity, neuroscience and enactivism. A new paradigm? In Education Sciences \& Society, v. 4, n. 1, 2013. 
GEE, James Paul; HAYES, Elisabeth. Nurturing Affinity Spaces and Game-Based Learning Games, Learning and Society. In STEINKUEHLER, Constance Steinkuehler; SQUIRE, Kurt; BARAB Sasha (orgs.) Learning and Meaning in the Digital Age. Cambridge: Cambridge University Press, 2012.

JENKINS, Henry. Confronting the Challenges of Participatory Culture: Media Education for the 21st Century. 2009.

MIRANDA, Lyana Virgínia Thédiga de. Multissensorialidades e aprendizagens: usos das tecnologias móveis pelas crianças na escola. 2013. Dissertação (Mestrado em Educação) - Programa de Pós-graduação em Educação, Universidade Federal de Santa Catarina, Florianópolis.

MARTÍN-BARBERO, Jesús. Ofício de cartógrafo. Travessias latino- americanas da comunicação na cultura. São Paulo: Edições Loyola, 2004.

MUCCHIELLI, Alex. Étude des communications: nouvelles approches, Armand Colin, Paris, 2006.

PISCHETOLA, Magda; MIRANDA, Lyana Thediga. Metodologias participativas e projeto UCA: a busca pela tecnologia como cultura. Perspectiva, Florianópolis, v. 33, n. 2, p. 545-572, dez. 2015. Disponível em: <https://periodicos.ufsc.br/>. Acesso em: 22 Abr. 2018.

WATRAS, Joseph. Should Children Learn to Solve Problems? Philosophical Studies in Education, v.42, p.36-43, 2011.

WINKIN, Yves. A nova comunicação: da teoria ao trabalho de campo. Campinas: Papirus, 1998. 